\title{
Compact Ultra Wide-Band and Tri-Band Antenna for Portable Device
}

\author{
Adnan GHAFFAR ${ }^{1}$, Wahaj Abbas AWAN ${ }^{2}$, Abir ZAIDI ${ }^{3}$, Niamat HUSSAIN ${ }^{4}$, \\ Syed Muhammad RIZVI $I^{5}$ Xue Jun $L I^{1}$ \\ ${ }^{1}$ Dept. of Electrical and Electronic Engineering, Auckland University of Technology, Auckland, New Zealand \\ ${ }^{2}$ Dept. of Integrated IT Engineering, Seoul National University of Science and Technology, South Korea \\ ${ }^{3}$ Dept. of Electrical Engineering Laboratory EEA \& TI, Hassan II University, Faculty of Science and Techniques (FSTM) \\ Mohammedia Casablanca, Morocco \\ ${ }^{4}$ Dept. of Computer and Communication Engineering, Chungbuk National University, Cheongju, South Korea \\ ${ }^{5}$ Dept. of Electrical Engineering, Beijing Jiaotong University, Beijing, China
}

hussain512@ieee.org

Submitted February 19, 2020 / Accepted September 4, 2020

\begin{abstract}
A compact ultra-wideband (UWB) and triband patch antenna with the partial ground plane is presented in this paper. Initially, the antenna is designed for UWB applications, operating at the UWB portion of the spectrum ranging from $3.1 \mathrm{GHz}$ to $10.6 \mathrm{GHz}$, then it is modified to operate at three distinct frequencies of $2.45 \mathrm{GHz}, 5 \mathrm{GHz}$, and $10.2 \mathrm{GHz}$. The proposed antenna is inspired by a classic rectangular patch antenna in which slots, stubs, and defected ground structure (DGS) were introduced to increase its operational bandwidth. Good results in terms of return loss are found in all resonant frequencies as well as for the single wideband. In addition, the proposed antenna has been compared with related works in the literature, to highlight its potential for future UWB and multiband portable devices.
\end{abstract}

\section{Keywords}

Compact size, UWB, triple-band, low profile antenna, DGS

\section{Introduction}

Antennas are considered to be the core component of a wireless communication system, as they represent the mean of transmission and reception of signals. Fundamentally, it represents the mechanism responsible for the transformation of the guided waves of the transmission line into space, over short distances (a few centimeters) as well as for long distances (hundreds of kilometers) [1]. These electronic components have been inspected, designed and improved for a large range of applications over the past few decades, where each application requires specific signal characteristics, among which the operational bandwidth is one of the most important parameters [2]. Therefore, three types of systems are defined in terms of the bandwidth parameter, namely narrow-band, broadband, and ultra- wideband (UWB) systems.

For decades, UWB antennas have attracted the attention of many researchers and antenna engineers around the globe, by dint of their large diversity of applications, including medical imaging, surveillance, body area networks, ground-penetrating radar (GPR) [3], [4]. UWB technology enables stream transmission of ultrashort pulses, which can be propagated through a very wide range of frequencies [5]. Also, UWB systems have some interesting features, including their ability to support a large amount of information and the fact that signals in the UWB frequency range $(3.1 \mathrm{GHz}$ to $10.6 \mathrm{GHz}$ according to the $\mathrm{FCC}$ ) are highly immune to interference. Moreover, UWB systems are strongly secure, since the short UWB pulses are more difficult to jam [6].

Several antennas for UWB systems have been reported in the literature [7-11]. In [7], a circular radiator loaded with stub and a parasitic patch was presented. The Defected Ground Structure (DGS) was utilized to achieve a wideband operation. In [8], the slotted Co-Planar Waveguide $(\mathrm{CPW})$ fed antenna with a double fractal structure was presented for the UWB systems. Although both antennas have wide impedance bandwidth along with good gain, both works have a drawback of a bigger dimension. In [9-11], a technique of defected radiator structure along with DGS is utilized in the design of a compact wideband antenna. However, the works reported in [9-11] have a setback of very complex structures which may increase the fabrication errors and are not preferable for mass production.

Although a huge work has been done on UWB antennas, UWB systems present some drawbacks, including their limited range (about 10 to $20 \mathrm{~m}$ ), which limits their implementation only for small scale deployments [12]. Besides, UWB systems suffer from multipath, since the power is divided over a large bandwidth [13]. Thus very few variations of radiation patterns along with a stable gain should be achieved for a successful implementation of 
antennas into UWB systems [7], [14]. Multiband antennas become a promising solution to overcome the issues associated with UWB antennas. Moreover, notching some frequencies from the UWB region may help to mitigate interference with co-existing sub-bands in the UWB portion of the spectrum such as wireless local area network (WLAN) operating from 4.94 to $5.925 \mathrm{GHz}$ and X-band $(8-12 \mathrm{GHz})$ [15]. Therefore, to take maximum advantage from this attractive band, multiband antennas in the UWB region are more preferable [16-20].

In [16], a slotted antenna loaded with a double Split Ring Resonator (SRR) structure is designed and proposed for tri-band applications. A tri-band operation is achieved successfully in this design but it has several drawbacks including structural complexity, narrow bands, and bigger dimension. In [17], a CPW fed antenna with a meandered line is used to achieve triband characteristics. The antenna shows good performance parameters in terms of size and gain stability but had set back of narrowband for first resonance. Another simple structured slotted CPW fed antenna was reported in [18], however, it does not provide wide bands and high gain characteristics. In [19], the presented antenna offers high gain and simple structure at the cost of narrow bands and a bigger dimension. The antenna presented in [20] has the advantage of triband, simple geometrical configuration, and stability in the radiation pattern. However, the antenna has several disadvantages including narrow bandwidth and low radiation efficiency.

It can be deduced from the literature review that the new designs of compact, planar UWB antennas would be a useful addition for UWB communication systems.

In this paper, we present a rectangular patch antenna which is modified by introducing slots and stubs in its radiating element and defected ground structures (DGS) in its ground plane for bandwidth enhancement. The presented antenna in this work is capable to operate in the triple-band as well as wideband behavior, which is beneficial for future portable devices. The rest of the paper is organized as follows: Antenna design is discussed in Sec. 2, antenna designing methodology was investigated in Sec. 3, measured results are presented in Sec. 4, and Section 5 concludes the proposed work.

\section{Antenna Topology and Design}

The geometry of the proposed tri-band antenna is shown in Fig. 1. The antenna geometry is engraved on cheap FR4-epoxy having a loss tangent of 0.02 and relative permittivity of 4.4. For ease of fabrication and testing standard, copper cladding of $0.035 \mathrm{~mm}$ is used. The overall size of the proposed antenna is $S_{\mathrm{x}} \times S_{\mathrm{y}} \times H$. A DGS technique is utilized for impedance matching and to enhance the operational bandwidth, the dimension of the DGS is $G_{\mathrm{x}} \times G_{\mathrm{y}}$. The radiator is fed using 50- $\Omega$ matching microstrip feeding with width $F_{\mathrm{x}}$ and length $F_{\mathrm{y}}$. The antenna geometry consists of the simple rectangular patch, which is modified using a rectangular slot $\left[P_{\mathrm{x}} \times\left(2 \times A_{\mathrm{y}}+g\right)\right]$ and

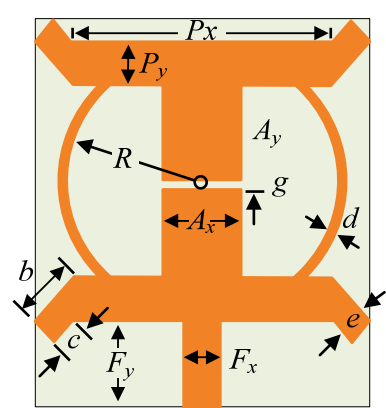

(a)

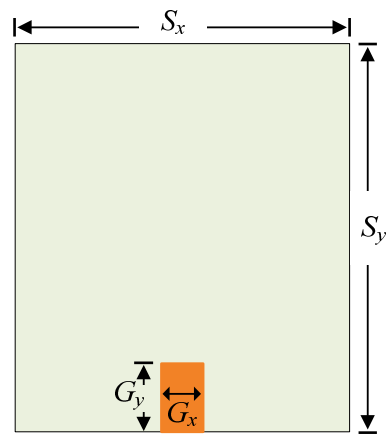

(b)
Fig. 1. Geometry of the proposed antenna: (a) top view and (b) bottom view.

\begin{tabular}{|c|c|c|c|c|}
\hline Parameter & $\begin{array}{c}\text { Value } \\
(\mathbf{m m})\end{array}$ & Parameter & $\begin{array}{c}\text { Value } \\
(\mathbf{m m})\end{array}$ \\
\hline$S_{x}$ & 18 & & $S_{y}$ & 18 \\
\hline$G_{x}$ & 2 & & $G_{y}$ & 3 \\
\hline$F_{x}$ & 2 & & $F_{y}$ & 4 \\
\hline$A_{x}$ & 4 & & $A_{y}$ & 4.4 \\
\hline$P_{x}$ & 14 & & $P_{y}$ & 2.05 \\
\hline$H$ & 1.6 & & $g$ & 0.2 \\
\hline$e$ & 1.4 & & $c$ & 1.4 \\
\hline$d$ & 0.2 & & $b$ & 2.9 \\
\hline
\end{tabular}

Tab. 1. Optimized dimensions of proposed antenna.

quadrilateral patches having the dimension of $e \times c$ are added at each corner of the radiator. Afterword, two semicircular stubs having a thickness of $d$ were inserted to provide a path to current to flow from the lower part to the upper part. In the last step, two rectangular patches having length $A_{\mathrm{y}}$ and width $A_{\mathrm{x}}$ were inserted having gap $g$ between them, inducing additional capacitive load between upper and lower resonating part hence introduce an additional lower resonance. The optimized dimensions of the proposed antenna are enlisted in Tab. 1.

\subsection{Design of the Wide-Band Antenna}

Monopole antennas being well known for their number of benefits including wide impedance bandwidth, omnidirectional radiation pattern, and stable gain. Initially, a quarter-wave monopole antenna was designed to cover the complete WLAN and Wi-Fi band of $5 \mathrm{GHz}$. The length $L_{\mathrm{fr}}$ of the monopole can be calculated by using the following equation given in [21]:

$$
L_{\mathrm{fr}}=\frac{c}{4 f_{\mathrm{r}} \sqrt{\varepsilon_{\mathrm{eff}}}} .
$$

$c$ is the speed of the light and $f_{\mathrm{r}}$ is the desired resonating frequency (for presented case $f_{\mathrm{r}}$ is chosen to be $5.8 \mathrm{GHz}$ ). $\varepsilon_{\text {eff }}$ is the effective dielectric constant, for monopole antenna it can be calculated using the following relation provided in [21]:

$$
\varepsilon_{\mathrm{eff}} \approx \frac{\varepsilon_{\mathrm{r}}+1}{2}+\frac{\varepsilon_{\mathrm{r}}+1}{2}\left(1+12\left(\frac{\omega}{h}\right)\right)^{-0,5}
$$

where $\varepsilon_{\mathrm{r}}$ is the dielectric constant, $\omega$ is the width and $h$ is the thickness of the substrate. 
In the next phase, a well-known technique to enhance the bandwidth named defected ground structure was deployed. An inverted U-shaped slot was truncated from the ground, leaving only a small rectangle of dimensions $G_{\mathrm{x}} \times G_{\mathrm{y}}$ from the whole ground plane. The presence of this slot affects notably the current distribution of the radiator, due to this change, the performance of antenna has improved significantly in terms of bandwidth and return-loss, for both higher and lower bands, as depicted in Fig. 2. A detailed discussion on the effect of current distribution on the antenna performance is presented in [22]. Figures 3(a-b) describe the effect of the DGS on antenna performance. It can be seen from Fig. 3(a) that the length $G_{y}$ is controlling the impedance bandwidth of the antenna, while width $G_{\mathrm{x}}$ of the DGS is dealing with the impedance matching, as depicted in Fig. 3(b), hence optimized parameters were chosen to achieve wider bandwidth along with good impedance matching at the resonating area.

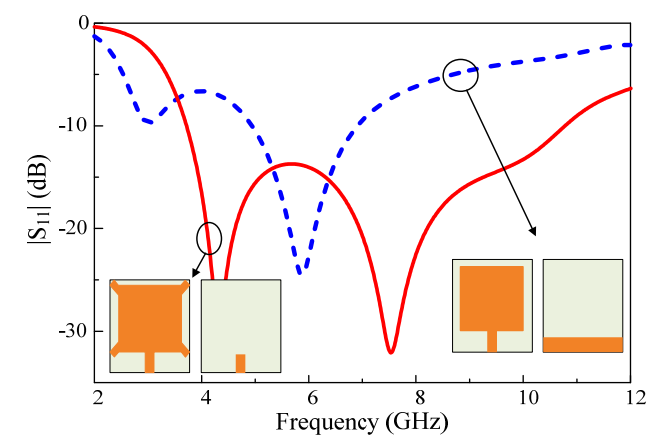

Fig. 2. Return loss comparison of conventional monopole antenna with modified UWB antenna.

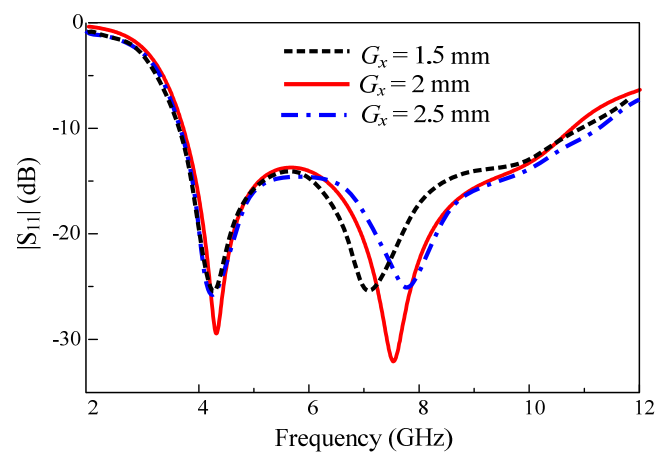

(a)

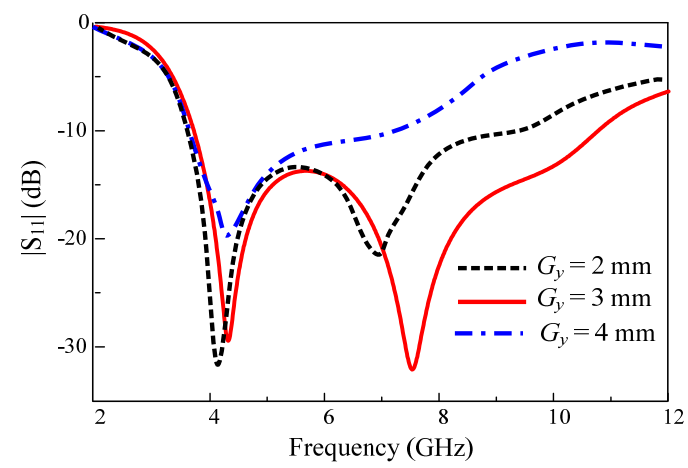

(b)

Fig. 3. Effects of ground structure on the impedance bandwidth of UWB antenna by changing (a) length $G_{\mathrm{y}}$, (b) width $G_{\mathrm{x}}$.

\subsection{Design of the Tri-Band Antenna}

As stated in the aforementioned discussion, due to several drawbacks of UWB antennas, multi-band antennas attain considerable attention. Band congestion and the presence of narrowband inside the UWB region cause a lot of unwanted interference due to which many modern-day devices are operating at several sub-bands of the UWB region. Therefore, to fulfill this demand, the proposed UWB antenna is converted into a tri-band antenna after three consecutive iterations, as depicted in Fig. 4(a).

In the first step, two rectangular slots were etched from the radiator, the introduction of these slots affects the current distribution and converts the UWB antenna into a tri-band antenna, as depicted in Fig. 4(b). The resultant antenna shows resonances at $3.85 \mathrm{GHz}, 7.8 \mathrm{GHz}$, and $10 \mathrm{GHz}$. The length $\left(2 A_{\mathrm{y}}+g\right)$ and width $\left(L_{\mathrm{x}}\right)$ of the rectangular slot were tuned carefully to get the maximum return loss at the notch bands. However, it is observed that the mitigation of the lower stopband around $5.8 \mathrm{GHz}$ is not so prominent.

Therefore, two semicircular shorted stubs were added in the next step, to enhance the stopband feature of the presented antenna. The addition of these semicircular stubs introduced an additional path for the flow of current from the lower part to the upper part. The surface charge distribution gets disturbs, thus results in further lowering the fundamental resonance along with mitigation of the WLAN band (4.9-6.1 GHz).

For mitigation of the desired band, the length of the semicircular stubs can be varied by increasing or decreasing the radius of the stubs. The resultant notch band due to the insertion of the semi-circular stubs can be estimated by using the following equation

$$
f_{\mathrm{r}}=\frac{c}{x L_{\mathrm{T}} \sqrt{\varepsilon_{\text {eff }}}}
$$

where $x$ is the factor that expresses the relation between the length of the stub and the wavelength $(\lambda)$ at the desired notch band, for the quarter-wave monopole antenna the value of $x$ should be $1 \leq x \leq 4$ [22]. For the proposed design the value of $x$ estimated to be 4 , which corresponds to a quarter wavelength at the notch band frequency. Moreover, the effective length of the stub $L_{\mathrm{T}}$ that can be calculated using the relation:

$$
L_{T}=\pi R+\frac{A_{\mathrm{x}}}{2}
$$

where constant $\pi=22 / 7 \approx 3.1416, R$ is the internal radius of the semicircular stub, and $A_{\mathrm{x}} / 2$ is the difference between the stub and the central part of the radiator. Hence, depending upon the user's demand prototype-II can be used for tri-band applications where mitigation of the WLAN band is necessary.

In the last step, to get the lower resonance at the wellknown industrial, scientific and medical (ISM) band (2.4 GHz-2.48 GHz) along with mitigation of $3 \mathrm{GHz}$ band 


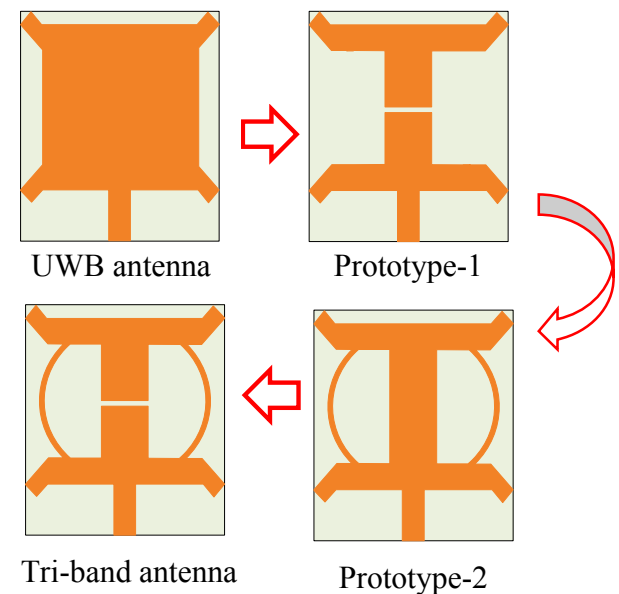

(a)

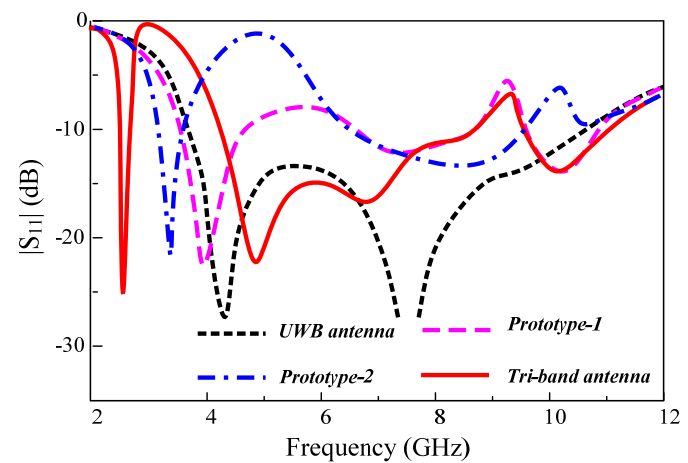

(b)

Fig. 4. The design evolution of the tri-band antenna from UWB antenna: (a) geometrical view and their (b) return loss comparisons.

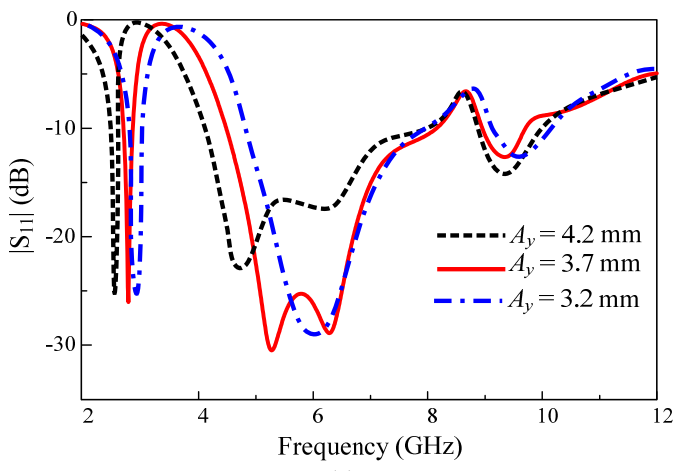

(a)

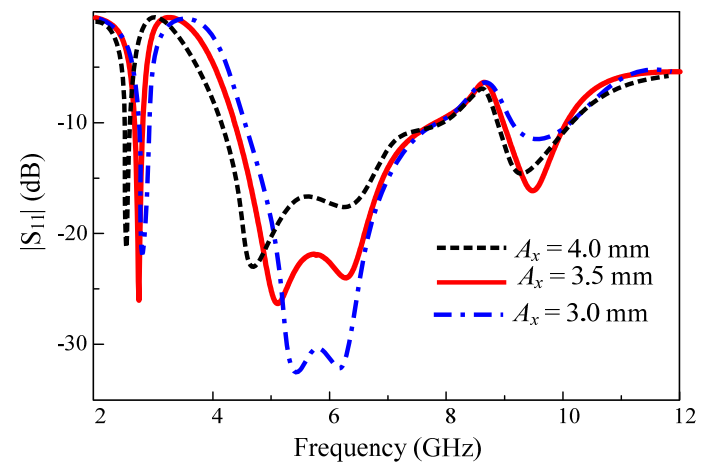

(b)

Fig. 5. Effects of various parameters on the first notch band of Tri-band antenna: (a) parameter $A_{\mathrm{y}}$, (b) parameter $A_{\mathrm{x}}$. spectrum allocated for WiMAX (3.3-3.8 GHz) and 5G sub6-GHz $(3.3-4.2 \mathrm{GHz})$ a rectangular slot is etched at the center of the radiator. The presence of this stub provides an additional capacitive load and thus results in lowering the first resonances as described in [23]. Here the width of the slot adjusts the additional capacitance and results in controlling the lower resonance. Furthermore, the rectangular slot also results in increasing the effective length of the stubs which is now given by the following relation

$$
L_{\mathrm{T}}=\pi R+A_{\mathrm{x}}+A_{\mathrm{y}}
$$

where $A_{\mathrm{x}}+A_{\mathrm{y}}$ represents the distance of shorted stub from the center of the radiator. Thus by adjusting the distance between stub and center of the radius, the effective length can be adjusted, hence the notch band can be controlled. It is worth noting that both equations (5) and (6) were extracted from the iterative method and curve fitting method. By using a similar process the value of $A_{\mathrm{x}}$ and $A_{\mathrm{y}}$ for the desired notch band can be estimated easily.

It can be seen from Fig. 5(a), that for the proposed triband antenna decreasing the value of the parameter $A_{\mathrm{y}}$ results in decreasing the value of $L_{\mathrm{T}}$ given by (6). Thus the central frequency $f_{\mathrm{r}}$ increases which verifies the relation presented in (4). A similar phenomenon is observed by varying the parameter $A_{\mathrm{x}}$, as depicted in Fig. 5(b).

\section{Results and Discussion}

Simulations of the proposed antenna were carried out using the finite element method (FEM) based electromagnetic solver, Higher Frequency Structural Simulator (HFSS). For validation of the proposed findings, a sample UWB and tri-band antenna prototype were fabricated using a standard chemical etching process. The antenna geometry was fabricated using commercially available FR4-epoxy having copper cladding of $0.035 \mathrm{~mm}$. Various antenna characteristics like return loss, radiation pattern and gain were measured and compared with simulated ones in this section, to validate our findings. The scattering parameters were measured using Vector Network Analyzer (VNA) model no. HP-8720D having a frequency range from $50 \mathrm{MHz}$ to $13.5 \mathrm{GHz}$. On the other hand, ETS-Lindgren (EMCO) type broadband horn antenna model no. 3115 ranging $1-12 \mathrm{GHz}$ was utilized to measure the gain and radiation pattern of the proposed antenna. The fabricated prototype of the antenna was placed $3 \mathrm{~m}$ away from the reference horn antenna inside the anechoic chamber for farfield measurements.

\subsection{Return Loss}

Figure 6(a) presents the comparison of simulated and measured scattering parameters of the proposed UWB antenna along with fabricated porotype. A good agreement between simulated and measured s-parameters is observed, moreover, the antenna covers an ultra-wide bandwidth of $6.95 \mathrm{GHz} \quad(3.85 \mathrm{GHz}-10.8 \mathrm{GHz})$ with reference to $\left|\mathrm{S}_{11}\right|<-10 \mathrm{~dB}$. On the other hand, Figure 6(b) depicts the 


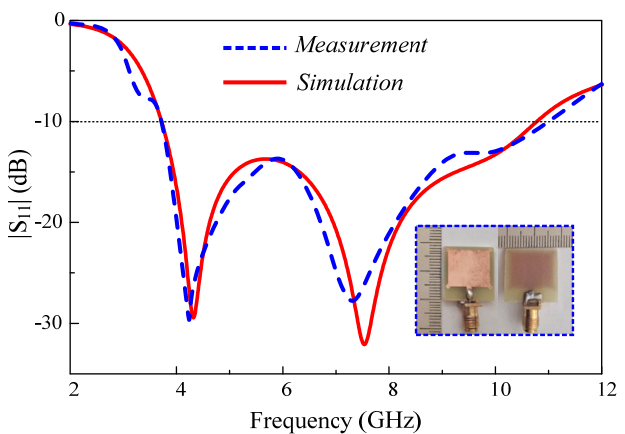

(a)

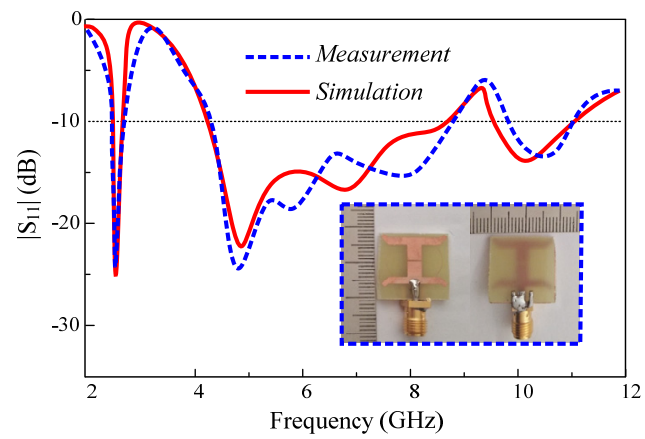

(b)

Fig. 6. Return loss comparison of simulated and measured (a) UWB antenna, (b) tri-band antenna.

comparison of simulated and measured S-parameters of the presented tri-band antenna along with its fabricated prototype. The measured results of the tri-band antenna show a good agreement with simulated results having resonances at $2.45 \mathrm{GHz}, 5 \mathrm{GHz}$, and $10.2 \mathrm{GHz}$. The measured bandwidth for $2.45 \mathrm{GHz}$ is $2.37-2.53 \mathrm{GHz}$ covering complete ISM band, for $5 \mathrm{GHz}$ it is $4.2-.64 \mathrm{GHz}$ covering various well-known bands of WLAN (5-6 GHz), Wi-Fi (5 GHz), ISM (5.725-5.875 GHz), Wi-Max $(5.8 \mathrm{GHz})$ along with a major portion of C-band $(4-8 \mathrm{GHz})$ and for $10.2 \mathrm{GHz}$ it is $9.2-11.4 \mathrm{GHz}$ covering a major portion of X-band $(8-12 \mathrm{GHz})$ used for space and satellite communications.

\subsection{Far-Field Parameters}

Figure 7 presents the radiation pattern (co-pole and cross-pole) of the proposed tri-band antenna at resonance frequencies of $2.45 \mathrm{GHz}, 5 \mathrm{GHz}$, and $10.2 \mathrm{GHz}$. The antenna shows an omnidirectional radiation pattern in principal $E$-plane $\left(\theta=0^{\circ}\right)$ and a bi-directional radiation pattern in principal $H$-plane $\left(\theta=90^{\circ}\right)$. Moreover, the good agreement between simulated and measured radiation patterns verify the findings. Moreover, a good cross-polarization isolation is observed at all frequencies. However, it increased a bit for $10.2 \mathrm{GHz}$ at $H$-plane. Figure 8(a) presents the maximum gain vs frequency plot of the UWB antenna. The presented work shows an average gain of $2 \mathrm{dBi}$ at operational bandwidth along with good matching with simulated results. The increase in the gain value for higher frequencies is due to an increase in the electrical size of the antenna at higher frequencies. Similarly, Figure 8(b) presents the measured gain of the proposed tri-band antenna,
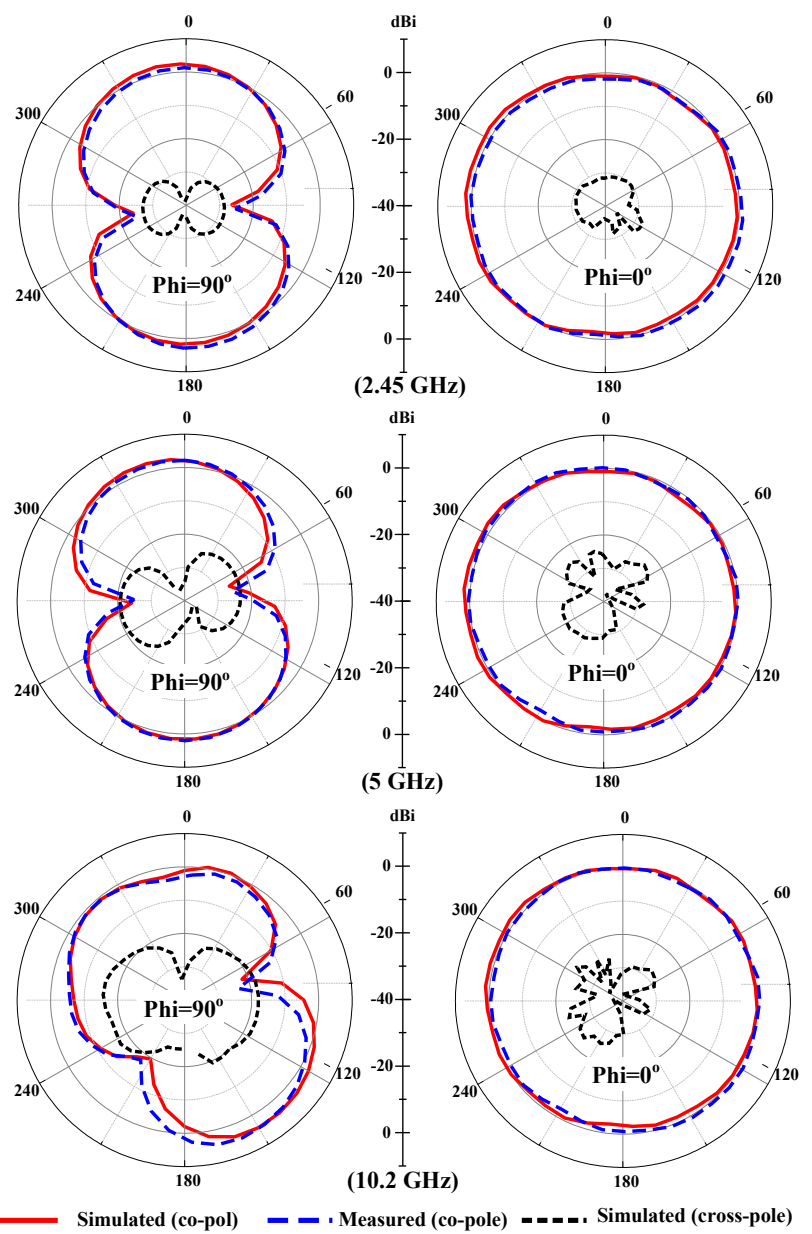

Fig. 7. Radiation patterns of the proposed tri-band antenna at different frequencies.

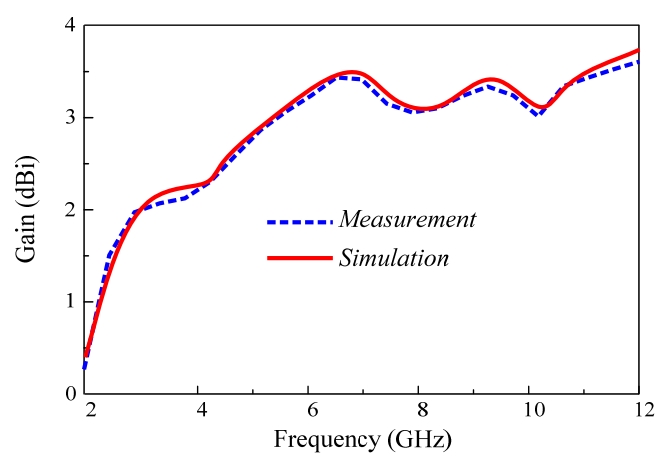

(a)

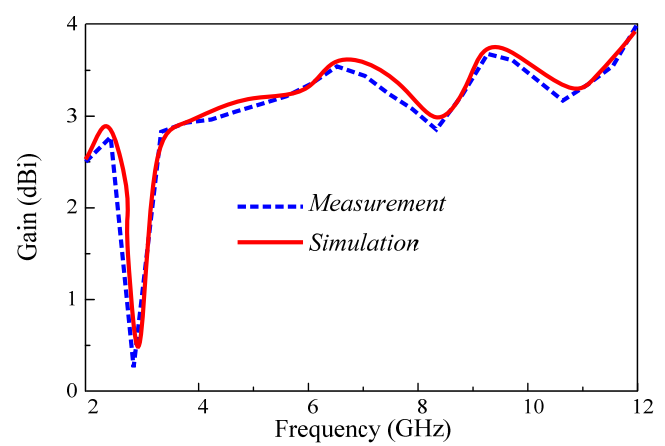

(b) 
Fig. 8. Simulated and measured peak gain of the proposed (a) UWB antenna and (b) tri-band antenna.

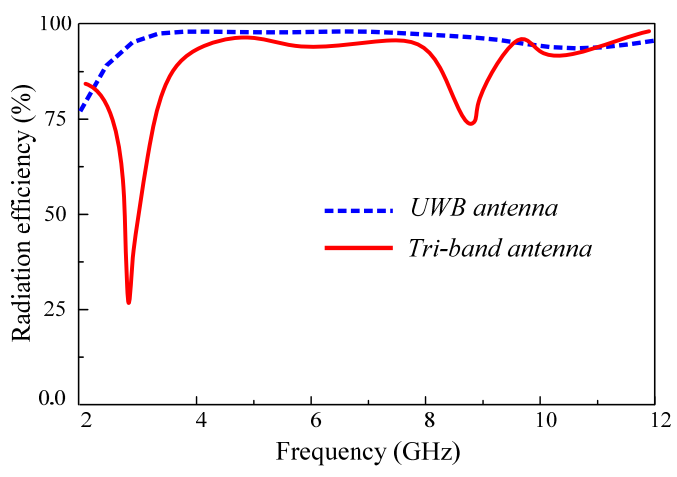

Fig. 9. Radiation efficiency of the proposed UWB antenna and tri-band antenna.

the antenna shows an average gain of $1.5 \mathrm{dBi}$ in the bandpass region while a minimum gain of $-8.3 \mathrm{dBi}$ is observed for the bandstop region. The simulated efficiency of the UWB and tri-band antenna is depicted in Fig. 9, the antenna shows the radiation efficiency of more than $86 \%$ in the bandpass region for both measured prototypes and minimum efficiency of $5.7 \%$ in the bandstop region for the tri-band antenna.

Table 2 shows the comparison of the proposed UWB antenna with other state of the art UWB antennas. It is observed that the proposed antenna offers a compact size as compared to other works [7-11]. The proposed antenna exhibited high gain and efficiency as compared to [7, 9-11]. Although [8-11] are offering wide bandwidths, they have complex geometrical structures. Thus, the proposed UWB antenna over-performs other related work showing the simple geometrical structure, compact size with ultra-wide bandwidth along with high gain and efficiency.

Table 3 shows the comparison parameters of the proposed antenna design with other tri-band antennas. The antenna is offering at least $32.5 \%$ miniaturization as compared to given tri-band antennas [16-20]. Moreover, its high efficiency, moderate gain, wide operational band, and omnidirectional radiation patterns are the key advantages of this design.

\section{Conclusion}

In this paper, a novel monopole antenna is presented. The proposed antenna is designed to operate in the UWB frequency band, then the radiating element is modified to configure the antenna behavior into tri-band using slots, stubs, and DGS introduced in the antenna structure. The presented prototype reported promising results in terms of return loss, bandwidth, radiation pattern, and efficiency. Moreover, a prototype of the proposed antenna was fabricated and subjected to experimental measurement, which showed that simulation and measurement results are in good agreement. Therefore, the proposed antenna is a potential candidate for future portable devices.

\section{References}

[1] LAHEURTE, J.M. (Ed.) Compact Antennas for Wireless Communication and Terminals. Hoboken (NJ): Wiley, 2011. ISBN: 978-1-118-60340-6

[2] GALVAN-TEJADA, G. M., PEYROT-SOlis, M. A., AGUILAR, H. J. Ultra Wideband Antennas: Design, Methodologies and Performance. Boca Raton (FL): CRC Press, 2015. DOI: $10.1201 / \mathrm{b} 18624$

[3] AKHTAR, F., NAQVI, S. I., ARSHAD, F., et al. A flexible and compact semicircular antenna for multiple wireless communication applications. Radioengineering, 2018, vol. 27, no. 3, p. 671-678. DOI: 10.13164/re.2018.0671

[4] AWAN, W.A., ZAIDI, A., HUSSAIN, N., et al. Stub loaded, low profile UWB antenna with independently controllable notchbands. Microwave and Optical Technology Letters, 2019, vol. 61, no. 11 , p. 2447-2454. DOI: $10.1002 /$ mop.31915

\begin{tabular}{|c|c|c|c|c|c|c|}
\hline Ref. & $\begin{array}{c}\text { Physical } \\
\text { Dimensions } \\
\left(\mathrm{mm}^{2}\right)\end{array}$ & $\begin{array}{c}\text { Dielectric } \\
\text { Constant }\end{array}$ & $\begin{array}{c}\text { Structural } \\
\text { Complexity }\end{array}$ & $\begin{array}{c}\text { Bandwidth } \\
(\mathrm{MHz})\end{array}$ & $\begin{array}{c}\text { Peak Gain } \\
(\mathrm{dBi})\end{array}$ & $\begin{array}{c}\text { Efficiency } \\
(\%)\end{array}$ \\
\hline$[7]$ & $50 \times 50$ & 4.4 & Moderate & 6000 & 3.8 & $<74$ \\
\hline$[8]$ & $32 \times 24$ & 4.4 & Moderate & 7400 & 4.8 & $<85$ \\
\hline$[9]$ & $20 \times 20$ & 4.4 & Complex & 8300 & 3.1 & $<68$ \\
\hline$[10]$ & $20 \times 20$ & 4.4 & Complex & 10500 & 3.2 & $<70$ \\
\hline$[11]$ & $15 \times 19$ & 4.4 & Complex & 11800 & 2.9 & $<59$ \\
\hline Prop. & $18 \times 18$ & 4.4 & Simple & 6990 & 3.9 & $<83$ \\
\hline
\end{tabular}

Tab. 2. Comparison of the proposed UWB antenna with state-of-the-art antennas.

\begin{tabular}{|c|c|c|c|c|c|c|}
\hline Ref. & $\begin{array}{c}\text { Physical } \\
\text { Dimensions } \\
\left(\mathrm{mm}^{2}\right)\end{array}$ & $\begin{array}{c}\text { Dielectric } \\
\text { Constant }\end{array}$ & $\begin{array}{c}\text { Electrical } \\
\text { Length } \\
\left(\lambda_{0}^{2}\right)\end{array}$ & $\begin{array}{c}\text { Bandwidth } \\
(\mathrm{MHz})\end{array}$ & $\begin{array}{c}\text { Peak Gain } \\
(\mathrm{dBi})\end{array}$ & $\begin{array}{c}\text { Efficiency } \\
(\%)\end{array}$ \\
\hline$[16]$ & $28 \times 20$ & 4.4 & $0.23 \times 0.17$ & $180 / 360 / 1870$ & $2.4 / 3.38 / 4$ & $<79$ \\
\hline$[17]$ & $24 \times 20$ & 4.4 & $0.19 \times 0.16$ & $90 / 1057 / 1489$ & $1.62 / 2.4 / 2.5$ & Not reported \\
\hline$[18]$ & $30 \times 34$ & 4.4 & $0.23 \times 0.26$ & $250 / 200 / 210$ & $-1 / 1 / 3.5$ & $<84$ \\
\hline$[19]$ & $28 \times 32$ & 4.4 & $0.23 \times 0.26$ & $250 / 475 / 1700$ & $3.8 / 4 / 3.1$ & $<83$ \\
\hline$[20]$ & $24 \times 20$ & 4.4 & $0.2 \times 0.18$ & $120 / 328 / 300$ & $1.3 / 3.3 / 2.2$ & $<71$ \\
\hline
\end{tabular}




\begin{tabular}{|c|c|c|c|c|c|c|}
\hline Prop. & $18 \times 18$ & 4.4 & $0.15 \times 0.15$ & $150 / 4440 / 2200$ & $1.4 / 3.4 / 3.9$ & $<86$ \\
\hline \multicolumn{8}{|c|}{$\lambda_{0}$ corresponds to free space wavelength at lower resonance }
\end{tabular}

Tab. 3. Comparison of the proposed tri-band antenna with state-of-the-art antennas.

[5] HUSSAIN, N., JEONG, M., PARK, J., et al. A compact size 2.9$23.5 \mathrm{GHz}$ microstrip patch antenna with WLAN band-rejection. Microwave and Optical Technology Letters, 2019, vol. 61, no. 5, p. 1307-1313. DOI: 10.1002/mop.31708

[6] CHAUDHARY, P., KUMAR, A. Compact ultra-wideband circularly polarized CPW-fed monopole antenna. AEU International Journal of Electronics and Communication, 2019, vol. 107, p. 137-145. DOI: 10.1016/j.aeue.2019.05.025

[7] DAS, A., ACHARJEE, J., MANDAL, K. Compact UWB printed slot antenna with three extra bands and WiMAX rejection functionality. Radioengineering, 2019, vol. 28, no. 3, p. 544-551. DOI: $10.13164 /$ re.2019.0544

[8] LI, Y., LI, W., JIANG, T. Implementation and investigation of a compact circular wide slot UWB antenna with dual notched band characteristics using stepped impedance resonators. Radioengineering, 2012, vol. 21, no. 1, p. 617-527. ISSN: 12102512

[9] HOTA, S., BAUDHA, S., MANGARAJ, B. B., et al. A novel compact planar antenna for ultra-wideband application. Journal of Electromagnetic Waves and Applications, 2020, vol. 34, no. 1, p. 116-128. DOI: 10.1080/09205071.2019.1689854

[10] BAUDHA, S., BASAK, A., MANOCHA, M., et al. A compact planar antenna with extended patch and truncated ground plane for ultra-wide band application. Microwave and Optical Technology Letters, 2020, vol. 62, no. 1, p. 200-209. DOI: 10.1002/mop.31988

[11] HOTA, S., BAUDHA, S., MANGARAJ, B. B., et al. A compact, ultrawide band planar antenna with modified circular patch and a defective ground plane for multiple applications. Microwave and Optical Technology Letters, 2019, vol. 61, no. 9, p. 2088-2097. DOI: $10.1002 /$ mop.31867

[12] ULLAH, U., KOZIEL, S. Design and optimization of a novel compact broadband linearly/circularly polarized wide-slot antenna for WLAN and Wi-MAX applications. Radioengineering, 2019, vol. 28, no. 1, p. 19-24. DOI: 10.13164/re.2019.0019

[13] HAMAD, E. K. I., NADY, G. Bandwidth extension of ultrawideband microstrip antenna using metamaterial double-side planar periodic geometry. Radioengineering, 2019, vol. 28, no. 1, p. 25-32. DOI: 10.13164/re.2019.0025

[14] NIYAMANON, S., JANPANGNGERN, P., PHONGCHAROENPANICH, C. Wideband dual-arm capacitively coupled patch antenna for tablet/laptop applications. Radioengineering, 2019 , vol. 28, no. 4, p. 671-679. DOI: 10.13164/re.2019.0671

[15] BARAD, D., BEHERA, S. Hybrid polarized microstrip antenna for multifrequency application. International Journal of $R F$ Microwave Computer-Aided Engineering, 2017, vol. 27, no. 7, p. 1-9. DOI: $10.1002 / \mathrm{mmce} .21117$

[16] AMEEN, M., KUMAR, R., MISHRA, N., et al. A compact triple band dual polarized metamaterial antenna loaded with double hexagonal SRR for WLAN/WiMAX applications. In International Conference on Antenna Innovations \& Modern Technologies for Ground, Aircraft and Satellite Applications (iAIM). Bangalore (India), 2017, p. 1-4. DOI: 10.1109/IAIM.2017.8402518

[17] FERTAS, F., CHALlal, M., FERTAS, K. Design and implementation of a miniaturized CPW-fed microstrip antenna for triple-band applications. In 5th International Conference on Electrical Engineering-Boumerdes (ICEE-B). Boumerdes (Algeria), p. 1-6. DOI: 10.1109/ICEE-B.2017.8192103

[18] JALALI, A. R., AHAMDI-SHOKOUH, J., EMADIAN, S. R. Compact multiband monopole antenna for UMTS, WiMAX, and WLAN applications. Microwave and Optical Technology Letters, 2016, vol. 58, no. 4, p. 844-847. DOI: 10.1002/mop. 29685
[19] LIU, G., LIU, Y., GONG, S. Compact tri-band wide-slot monopole antenna with dual-ring resonator for WLAN/WiMAX applications. Microwave and Optical Technology Letters, 2016, vol. 58, no. 5, p. 1097-1101. DOI: 10.1002/mop.29759

[20] ACHARJEE, J., KUMAR, R. L., MANDAL, K., et al. A compact multiband multimode antenna employing defected ground structure. Radioengineering, 2019, vol. 28, no. 4, p. 663-670. DOI: $10.13164 /$ re.2019.0663

[21] IQBAL, A., SMIDA, A., ABDULRAZAK, L. F., et al. Lowprofile frequency reconfigurable antenna for heterogeneous wireless systems. Electronics, 2019, vol. 8, no. 9, p. 1-11. DOI: 10.3390/electronics8090976

[22] BALANIS, C. A. Advanced Engineering Electromagnetics. John Wiley \& Sons, 1999.

[23] UR RAHMAN, M., NAGSHVARIAN JAHROMI, M., MIRJAVADI, S. S., et al. Compact UWB band-notched antenna with integrated bluetooth for personal wireless communication and UWB applications. Electronics, 2019, vol. 8, no. 2, p. 1-13. DOI: $10.3390 /$ electronics 8020158

\section{About the Authors ...}

Adnan GHAFFAR received his B.Sc. in Computer Engineering, and M.S. in Circuits \& Systems from BZU Multan, Pakistan, and Lanzhou Jiaotong University, Lazhou, China in 2010 and 2015, respectively. He is pursuing his Ph.D. in Electrical and Electronics Engineering from Auckland University of Technology, Auckland, New Zealand. His research area includes RF circuits, reconfigurable antenna, embedded system, metasurface antenna, flexible, and wearable antenna design.

Wahaj Abbas AWAN received his B.S. degree in Electrical Engineering from the COMSATS University Islamabad, Sahiwal Campus, in 2019. He is currently pursuing the M.S. degree in integrated IT engineering with the Seoul National University of Science and Technology, Seoul, South Korea, where he is also a Research Assistant with the Electromagnetic Measurement and Application (EMMA) Laboratory. He is the author of more than 20 peer-reviewed conference and journal articles. His research interests include electrically small, flexible and reconfigurable antennas.

Abir ZAIDI received her licence degree in Electronics, Telecommunications and Computer Systems at Fez University of Sciences and Technology, then she had got a Master's degree in Microelectronics, Telecommunication and Industrial Data Processing at the same University in 2012 and 2015, respectively. She had completed her Ph.D. from Laboratory of Electronics, Energy, Automatics and Data Processing (EEA\&TI) Hassan II University, Mohammedia-Casablanca, Morocco in 2020. Her works studies and interests are focused on the design and the optimization of the performance of single and multiband, reconfigurable antennas for $5 \mathrm{G}$ applications. 
Niamat HUSSAIN (corresponding author) is currently pursuing his Ph.D. in Information and Communication Engineering at Chungbuk National University, Chungju-si, Korea. He was received Best Paper award in 2017, for his presented paper at Korea Winter Conference. His research is mainly focused on lens-coupled antennas, metasurface antennas, metamaterial antennas, UWB antennas, mmWave antennas and terahertz antenna.

Syed Muhammad RIZVI recived his B.S. degree from Usman Institue of Technology and first Master's degree from NED University of Engineering and Technology in 2014 and 2016, respectively. He is currently pursuing his Master's in Electrical Engineering from Beijing Jiaotong University, Beijing, China. His research is mainly focused on advance communication systems and electrically small antennas.

Xue Jun LI received his B.Eng. (First Class Honors) and Ph.D. in Electrical and Electronic Engineering from Nan- yang Technological University (NTU), Singapore, in 2004 and 2008, respectively. Between November 2007 and July 2008, he worked as Research Engineer and then as Research Fellow in Network Technology Research Centre, NTU. Between August 2008 and September 2008, he worked as Research Scientist in Temasek Laboratories @ NTU. From September 2008 to May 2011, he was with School of Electrical and Electronic Engineering, NTU as a faculty member. Between June 2011 and January 2013, he worked as Research Scientist in Institute for Infocomm Research $\left(\mathrm{I}^{2} \mathrm{R}\right)$, Agency for Science, Technology and Research (A*STAR), Singapore. Since January 2013, he has been with Department of Electrical and Electronic Engineering, School of Engineering, Auckland University of Technology (AUT), where he is a Senior Lecturer. His research interests include design/analysis of wireless networking protocols, modelling/design of radio frequency integrate circuits, and system optimizations. 